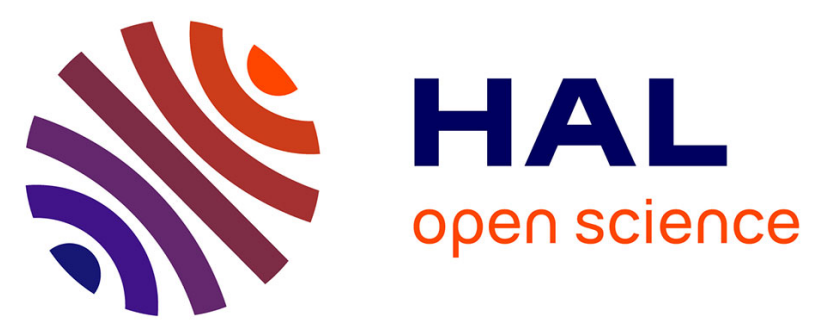

\title{
The Click Test: A Novel Tool to Quantify the Age-Related Decline of Fast Motor Sequencing of the Thumb
}

Florian Bodranghien, Hélène Mahé, Benjamin Baude, Maroi Manto, Yves Busegnies, Stéphane Camut, Christophe Habas, Peter Mariën, Giovanni de Marco, Kim van Dun

\section{To cite this version:}

Florian Bodranghien, Hélène Mahé, Benjamin Baude, Maroi Manto, Yves Busegnies, et al.. The Click Test: A Novel Tool to Quantify the Age-Related Decline of Fast Motor Sequencing of the Thumb. Current Aging Science, 2017, 10 (4), 10.2174/1874609810666170511100318 . hal-02310540

\section{HAL Id: hal-02310540 \\ https://hal.parisnanterre.fr/hal-02310540}

Submitted on 10 Oct 2019

HAL is a multi-disciplinary open access archive for the deposit and dissemination of scientific research documents, whether they are published or not. The documents may come from teaching and research institutions in France or abroad, or from public or private research centers.
L'archive ouverte pluridisciplinaire HAL, est destinée au dépôt et à la diffusion de documents scientifiques de niveau recherche, publiés ou non, émanant des établissements d'enseignement et de recherche français ou étrangers, des laboratoires publics ou privés. 


\title{
The Click Test: A Novel Tool to Quantify the Age-Related Decline of Fast Motor Sequencing of the Thumb
}

\author{
Florian Bodranghien ${ }^{1}$, Hélène Mahé ${ }^{2}$, Benjamin Baude ${ }^{2}$, Mario Manto ${ }^{1,2,3,}$, Yves Busegnies ${ }^{2}$, \\ Stéphane Camut ${ }^{2}$, Christophe Habas ${ }^{4}$, Peter Mariën ${ }^{5,6}$, Giovanni de Marco ${ }^{7}$ and Kim van Dun ${ }^{5}$
}

${ }^{1}$ Unité d'Etude du Mouvement GRIM, FNRS, ULB-Erasme, Route de Lennik, Bruxelles, Belgium; ${ }^{2}$ HELB, Campus Erasme, Route de Lennik, Bruxelles, Belgium; ${ }^{3}$ Service des Neurosciences, Université de Mons, Mons, Belgium; ${ }^{4}$ Service de Neurimagerie, CHNO Quinze-Vingts, Paris, France; ${ }^{5}$ Clinical and Experimental Neurolinguistics, Vrije Universiteit Brussel, Brussels, Belgium; ${ }^{6}$ Department of Neurology and Memory Clinic, ZNA Middelheim, Antwerp, Belgium; ${ }^{7}$ Laboratoire CeRSM (EA-2931), Equipe "Analyse du Mouvement en Biomécanique, Physiologie et Imagerie ». Université Paris Ouest, Nanterre, France

\begin{abstract}
Background: The thumb plays a critical role for manual tasks during the activities of daily life and the incidence of neurological or musculoskeletal disorders affecting the voluntary movements of the thumb is high in the elderly. There is currently no tool to assess repetitive motor sequencing of the thumb during ageing.

Objectives: To report a novel procedure (the Click Test) assessing the effects of ageing on fast motor sequencing of the thumb.

Methods: Healthy subjects $(\mathrm{n}=252$; mean age +/- SD: $49.76+/-19.97$ years; range: $19-89$ years; F/M: 151/101) were asked to perform fast repeated flexion/extension movements of the thumb using a mechanical counter.

Results: Motor performances (assessed by the number of clicks during 3 time periods: 15, 30 and $45 \mathrm{sec}$ ), significantly decreased as a function of age for both the dominant (age effect; $p<0.0001$ for 15,30 and $45 \mathrm{sec}$ ) and the non-dominant hand ( $<<0.0001$ for 15, 30 and $45 \mathrm{sec}$ ). The number of clicks was significantly higher in males (gender effect; $p<0.001$ ) and was higher on the dominant side as compared to the non-dominant side (handedness effect: $\mathrm{p}<0.001$ ). The Click Test is characterized by high repeatability (coefficients of variation from 3.20 to $4.47 \%$ ), excellent intra-rater reliability (intra-class coefficients ICC ranging from 0.89 to 0.98 ), high inter-rater reproducibility (Pearson's product correlation ranging from 0.85 to 0.96), high internal consistency (Cronbach alpha coefficient $=0.95$ ) and is highly correlated in terms of relative performances with the box and block test and the 9-hole peg test (positive linear correlation with the results of the box and block test: $\mathrm{p}<0.001$ for 15,30 and $45 \mathrm{sec}$ for both the dominant and the non-dominant hand; negative linear correlation with the results of the 9-hole peg test: $\mathrm{p}<0.001$ for 15,30 and $45 \mathrm{sec}$ for both the dominant and the non-dominant hand).

Conclusion: The Click Test is an entirely novel and very low cost tool to reliably discriminate the ageing effects upon the performances during fast repetitive motor sequencing of the thumb. The potential clinical and research applications for motor functions are multiple, especially in acute and chronic neurological disorders affecting the thumb as well as in the field of rheumatology and orthopedics.
\end{abstract}

A R T I C L E H IS T O RY

Received: November 30, 2016 Revised: April 28, 2017 Accepted: April 29, 2017

DOI:

$10.2174 / 1874609810666170511100318$

Keywords: Movements, sequencing, mechanical counter, hand, ageing, performances.

\section{INTRODUCTION}

The thumb plays a major role in the activities of daily life (ADL) requiring the use of the hand. There is a high incidence of neurological or musculoskeletal disorders affecting the voluntary movements of the thumb in the elderly [1].

*Address correspondence to this author at the Unité d'Etude du Mouvement (UEM), FNRS, ULB-Erasme, 808 Route de Lennik, 1070 Bruxelles, Belgium; Tel/Fax: 32-2-555.39.92; E-mail: mmanto@ulb.ac.be
In addition, we now observe in the clinic children, adolescents and young adults who develop symptoms related to an overuse of the thumb during daily tasks [2]. In particular, young adults are at risk for smartphones/electronic devices (iPod) thumb injuries (so-called «i-injuries»). Still, we currently lack a simple and standardized procedure to quantify the performances associated with fast repetitive sequencing movements of the thumb in a laboratory or a clinical setting. The Finger Tapping Test (FTT; the palm of the hand is kept 
on a table while the index presses a layer) is used to assess tapping rates of the index finger but does not evaluate the thumb which is preferentially affected by disorders such as systemic sclerosis for instance [3, 4]. Rehabilitation teams currently lack a procedure to monitor specifically the thumb performances in patients after a stroke involving the middle cerebral artery, keeping in mind (a) the somatotopic organization of the primary motor cortex (M1) reported about 70 years ago and which is characterized by a heavier representation of thumb muscles [5] and (b) intracortical efferent zones dedicated to thumb movement, especially for thumb flexion [6]. Indeed, stroke may impair predominantly thumb flexion/extension, with a relative sparing of adduction and abduction, confirming earlier findings in monkeys using microstimulation $[6,7]$. Such a test should be reliable, reproducible, easy to perform without being time-consuming, especially for applications in the clinic.

A novel procedure to quantify the performances of visually-guided pointing movements (involving proximal and distal joints) towards fixed targets (mechanical counters) located in the vertical plane using a portable platform (CAM test) was reported recently [8]. The following observations were made (1) a highly significant linear correlation between motor performance (number of clicks) and test duration; (2) a significant decline in performances in the elderly; (3) a better performance on the dominant side as compared to the non-dominant side (handedness effect). Durations of 15,30 and $45 \mathrm{sec}$ were used to establish normative data because a drop in performances is observed above the threshold of about $50 \mathrm{sec}$ in healthy subjects due to fatigue. The agerelated decline in performance was explained by the greater difficulties encountered by older subjects to perform multijoint coordinated movements, in particular when the task requires a combination of a fast oculomotor movement (saccade) with a limb movement [9-11]. The motor sequencing itself (succession of elementary motor contractions) is affected by the impaired limb proprioception in ageing [1218]. The loss of mass of the neuromuscular system which occurs during ageing is associated with a motor unit remodeling characterized by atrophy of muscle fibers, a higher number of fibers per motor unit, increased branching of presynaptic nerve terminals and redistribution of receptor sites at the post-synaptic level [19]. The functional consequences include reduced strength of the endplate potentials during stimulation of the motoneurons. Overall, both fine and gross motor performances are impacted by the natural process of ageing, due to changes in the motor unit behavior [20]. The differences in performances between the dominant and the non-dominant hand have been attributed to asymmetry in the neural control of motor units: lower average firing rates of lower motoneurons, lower recruitment thresholds and greater firing rate/force delay in the dominant hand as compared to the non-dominant hand [21]. In addition, predictive mechanisms of movement on the dominant side are more efficient $[22,23]$.

We report on a novel method to characterize fast repetitive movements of the thumb (flexion/extension sequencing) with the aims of (a) assessing whether age has a significant impact on performances and whether a handedness effect might be detected; and (b) providing normative values for the follow-up of neurological disorders or diseases of the musculoskeletal system during rehabilitation programs or specific therapies administered to improve thumb functions.

\section{MATERIALS AND METHODS}

Each study participant was provided with an oral explanation of the full procedure and signed a written informed consent. We recruited healthy subjects on the Erasme University Campus and in residency services of Brussels Region. The cohort can thus be considered as a convenience sample. The study was approved by the ethical committee of ULB-Erasme. All the adults included in the study had no restriction of activity as a consequence of a disease [24]. The following exclusion criteria were applied (these disorders are known to impair neural motor control or affect the musculoskeletal system of the thumb):

-History of fracture of the forearm or hand.

-Tendinitis in the forearm or hand within 12 months.

-History of arthritis in the upper limb.

-Carpal tunnel syndrome.

-Peripheral neuropathy.

-Stroke.

-Parkinson's disease.

-Alzheimer's disease.

-History Of a brain tumor.

-Alcohol intake within 6 hours preceding the experiment.

-Cocaine or heroin intake.

-Cannabis intake within 24 hours before the assessment.

Handedness was formally assessed by means the Edinburgh inventory using previously reported cut-offs to distinguish right-handed, left-handed and ambidextrous subjects $[8,25]$. The Cochin scale was used as a functional measure of the ability of the hand [26]. This scale includes 18 items based on questions concerning activities commonly performed by the hand in a person's daily environment (total score from 0 to 90 ). Although this scale is commonly used in the clinic to monitor the effects of therapies in the rheumatoid hand [27], the results of the effects of ageing in a group of healthy subjects have not been reported so far. For each subject, the following parameters were also collected (see supplementary file): height and weight (to compute the Body Mass Index (BMI)), size of the right and the left hand (to confirm the absence of any asymmetry which might influence the performances).

Fig. (1) illustrates the experimental set-up applied in the study cohort consisting of 252 subjects. The subject is comfortably seated in a quiet room. One mechanical counter (Upgreen counter-model FM40047 certified ISO9001; mass of $66 \mathrm{gr}$, size: diameter of $45 \mathrm{~mm}$, width $30 \mathrm{~mm}$ ) is held in the hand as illustrated. The forearm is lying on the thigh to avoid the confounding effect of an isometric contraction of arm muscles such as the biceps. Each hand is assessed separately. The repetitive flexions of the thumb are performed successively as fast as possible during three durations (15, 30 and 45 seconds; Dominant side: T15 Dom, T30 Dom, T45 Dom; Non-Dominant side: T15 Non Dom, T30 Non Dom, 


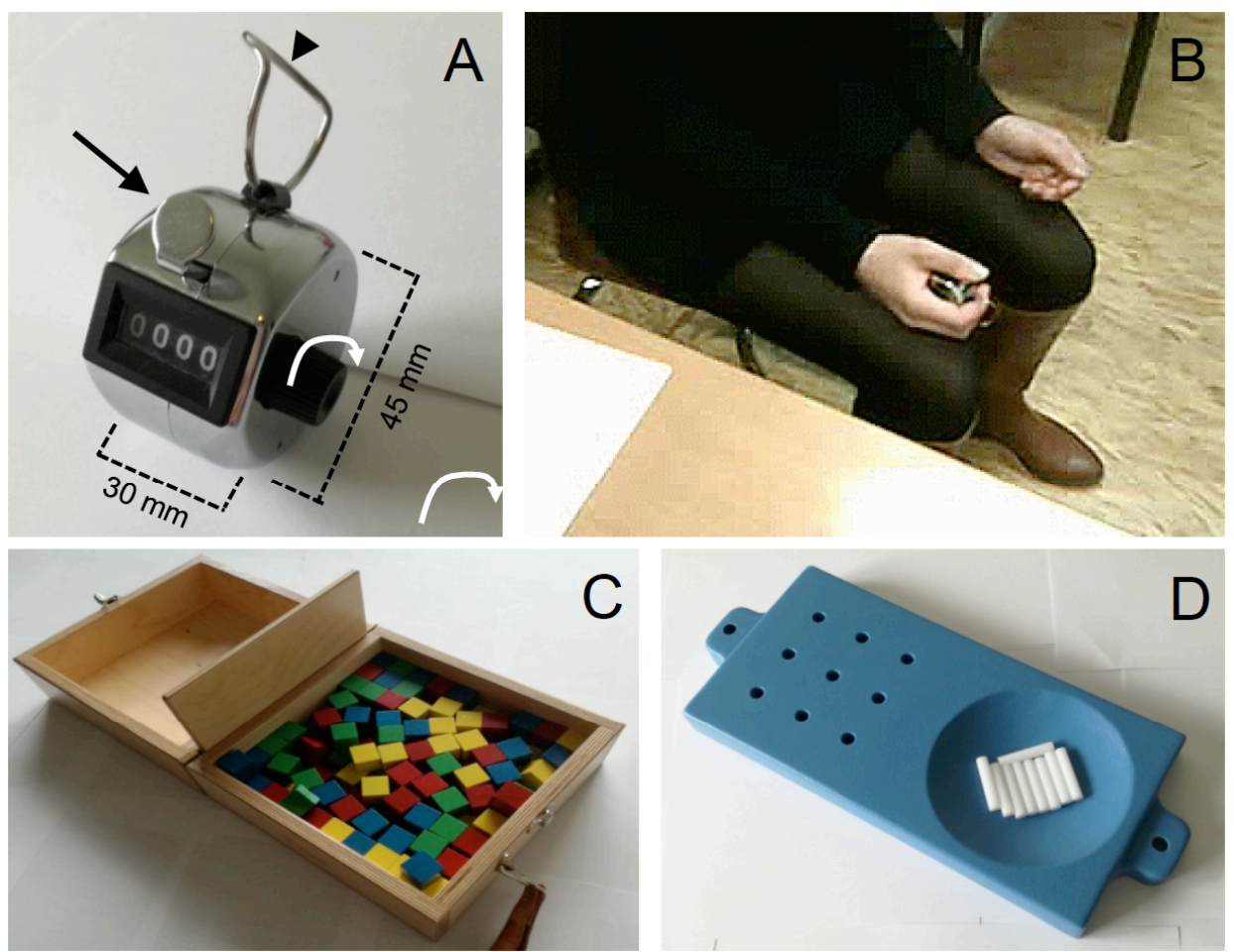

Fig. (1). Experimental procedure. A: mechanical counter. The black arrow indicates the push button. The lateral knob is turned (white arrow) to reset the score after the period of successive clicks. Dimensions of the counter are given. B: illustration of a subject with the counter in the right hand. The metallic ring (see the arrowhead in $\mathbf{A}$ ) surrounds the index finger. $\mathbf{C}$ : box and block test (BBT) consisting of a box divided by a partition into 2 compartments. Participants have to move a maximum number of blocks (100 wooden blocks; dimension of a block: $2.5 \mathrm{~cm})$ across the partition within $60 \mathrm{sec}$. D : 9-hole peg test. The board with 9 holes and a container with 9 pegs is shown. Pegs are picked up and put in the pegboard and returned to the container afterwards. The time taken to complete the test is recorded.

T45 Non Dom). We selected these durations on the basis of (1) our previous experience with the horizontal pointing test [28] and the CAM test [8]; and (2) the observation that most healthy adults report fatigue and show a decrease of motor performances (meaning a clear decrease in the rate of number of clicks on the counters) during successive pointing movements which outlast 50-55 sec [28]. As a consequence, we decided not to use a test duration longer than 50 seconds to avoid the drop in performance associated with fatigue in the upper limb. The mechanical counter requires a flexion/extension of the thumb of at least $9 \mathrm{~mm}$ to obtain an increment of the score after a click. A full extension of the thumb is not required. A flexion-extension movement of the inter-phalangeal joint along with a movement of the carpometacarpal joint occurs. The subjects adapt the movements according to comfort constraints and spontaneously keep the thumb on the counter in the majority of cases although some perform extensions in the range of 20-25 $\mathrm{mm}$.

For each period of time $(15,30$ and $45 \mathrm{sec})$, we recorded the number of successful clicks on the counter (a click is successful when the counter display shows an increment of $1)$. The counter was manually reset to zero after each measurement using a resetting knob located laterally on the counter. Subjects were instructed to click as quickly as possible on the mechanical counter after a "go" signal given orally (the emphasis was put on speed). They were asked to stop clicking after an oral "stop" signal. The examiner used a chronometer for the "go" and "stop", and subjects were unaware of the time during the procedure. Each subject was allowed to perform a practice trial of 10 seconds with each hand to become familiar with the task. A longer practice trial $(30 \mathrm{sec})$ or the succession of 3 practice trials with a rest period of 20 seconds between trials did not improve the performance (this was determined in a preliminary experiment with 5 subjects). Between each measurement, a resting period of 20 seconds was used to avoid fatigue. During the execution of the successive flexions/extensions of the thumb, the upper limb was recorded using a webcam linked to a laptop computer to record motor behavior and identify any participant who would not execute the task appropriately in a continuous fashion. It should be emphasized that previous assessments with the horizontal pointing test have shown that (1) there is no influence of the first side (right or left) investigated in terms of performances on the contralateral side (left or right, respectively); and (2) a rest period between each assessment avoids carry-over effects due to fatigue. The total time to administer the entire test is about 15 minutes (this includes the time to explain all the procedures, to estimate hand dominance, to fill in the Cochin questionnaire and the motor assessment itself). Scores of each counter were inserted in a dedicated Excel spread sheet.

\section{DEMOGRAPHICS}

Table 1 lists the demographics of the study population. We assessed the Click Test in 252 subjects (mean age +/SD: 49.76 +/- 19.97 years; range: $19-89$ years; F/M: 151/101). The majority of subjects were right-handed $(\mathrm{n}=$ 205 subjects with a laterality quotient $<-40$; left-handed sub- 
Table 1. Demographics of the subjects $(n=252$ subjects $)$.

\begin{tabular}{|c|c|c|c|c|c|c|c|c|c|c|}
\hline \multirow{3}{*}{$\begin{array}{c}\text { Age } \\
\text { (Years) }\end{array}$} & \multicolumn{5}{|c|}{ Women } & \multicolumn{5}{|c|}{ Men } \\
\hline & \multirow{2}{*}{$\mathbf{n}^{*}$} & \multirow{2}{*}{ Mean Age (SD) } & \multicolumn{3}{|c|}{ Handedness** } & \multirow{2}{*}{ n* } & \multirow{2}{*}{ Mean Age (SD) } & \multicolumn{3}{|c|}{ Handedness $* *$} \\
\hline & & & $\mathbf{R}^{\#}$ & $\mathbf{L}^{\#}$ & $\mathbf{A}^{\#}$ & & & $\mathbf{R}^{\#}$ & $\mathbf{L}^{\#}$ & $\mathbf{A}^{\#}$ \\
\hline $19-29$ & 35 & $23.69(3.29)$ & 24 & 5 & 6 & 20 & $24.20(2.98)$ & 15 & 1 & 4 \\
\hline $30-39$ & 17 & $34.41(3.55)$ & 16 & 1 & - & 15 & $33.53(2.95)$ & 10 & 2 & 3 \\
\hline $40-49$ & 27 & $44.70(2.85)$ & 22 & 4 & 1 & 14 & $44.79(2.64)$ & 11 & 2 & 1 \\
\hline $50-59$ & 19 & $53.84(3.20)$ & 14 & 4 & 1 & 21 & $53.90(2.45)$ & 19 & - & 2 \\
\hline $60-69$ & 20 & $64.40(3.20)$ & 17 & 1 & 2 & 14 & $65.14(3.18)$ & 12 & 2 & - \\
\hline $70-79$ & 14 & $73.57(2.93)$ & 13 & 1 & - & 8 & $73.75(3.45)$ & 6 & - & 2 \\
\hline $80-89$ & 19 & $83.11(1.52)$ & 17 & 1 & 1 & 9 & $83.44(3.13)$ & 9 & - & - \\
\hline $19-89$ & 151 & $49.94(20.57)$ & 123 & 17 & 11 & 101 & $49.50(19.14)$ & 82 & 7 & 12 \\
\hline
\end{tabular}

*Number of subjects. **Determined on the basis of the Edinburgh inventory. ${ }^{*} \mathrm{R}$ : Right-handed, L: Left-handed, A: Ambidextrous.

jects with a laterality quotient $>40: n=24$ subjects; ambidextrous: $n=23$ subjects). A subgroup of 60 subjects (mean age +/- SD: 49.00 +/- 20.19 years; range $20-89$ years; F/M: 39/21) participated to the evaluation of the relative performances between the Click Test with 2 tests widely disseminated to assess dexterity (box and block test, 9-hole peg test) $[24,29]$.

\section{REPEATABILITY, INTRA-RATER RELIABILITY, INTER-RATER REPRODUCIBILITY, INTERNAL CONSISTENCY AND RELATIVE PERFORMANCES OF THE CLICK TEST}

As reported in the literature [30] 3 measurements for each side and each test duration $(15,30$ and $45 \mathrm{sec})$ were carried out during one session in 10 subjects (mean age $+/$ SD: $39.6+/-14.67$ years; F/M: 5/5) to compute the coefficient of variation ( $\mathrm{CV}=\mathrm{SD} /$ mean $)$. To assess intra-rater reliability, one measurement for each side and each test duration $(15,30$ and $45 \mathrm{sec})$ was carried out during 4 successive days in 15 subjects (mean age +/- SD: 29.87 +/- 12.05 years; F/M: $7 / 8$ ) in order to compute the Intra-Class Coefficient (ICC), the preferred method for continuous data [30, 31]. Responsiveness (the responsiveness domain reflects the sensitivity to changes) was measured with the effect size (the effect size is based on the data distribution and corresponds to the mean difference between values obtained during the first and second assessments, divided by the SD of the values in the first assessment) [32]. For the inter-rater reproducibility, two observers performed a test-retest assessment in 10 subjects (mean age +/- SD: $37.3+/-16.16$ years; F/M: 5/5) participating in 2 sessions on the same day, with an interval of about 10 minutes between the 2 procedures. Each observer was unaware of the results obtained by the other. The preferred method is the correlation coefficient which should exceed $0.70[30,33]$. For the internal consistency, the Cronbach alpha coefficient (a measure of scale reliability to estimate the extent to which items in a test measure the same concept or construct [34]) was computed taking into account one measurement for each side and each test duration $(15,30$ and $45 \mathrm{sec})$.

For the assessment of relative performances with widely used tests, a group of 60 subjects (mean age +/- SD: 49.0 +/20.19 years; F/M: 39//21) performed the Click Test as well as two validated tests: the box-and-block test (a test assessing gross manual dexterity) and the 9-hole peg test (a test assessing fine manual dexterity) [24, 29]. The Intra-class Correlation Coefficients (ICC) related to test-retest reliability are high for the box-and-block test and the 9-hole peg test (0.85 to 0.98 ) [35]. A rest period of 2 minutes was used between each of these 3 procedures. The sequence of the 3 procedures was determined randomly.

\section{STATISTICS}

Descriptive statistics were performed using Sigmastat $\AA$ Software (Jandel Scientific, Germany) and were applied to the whole group of 252 subjects. The normality of the data was assessed using the Kolmogorov-Smirnov test.

For the whole group of subjects $(n=252)$, in order to compare age and handedness between men and women (gender effect), the Mann-Whitney rank sum test was applied. To assess the relationship between mean age per decade and mean Cochin score per decade, an exponential fitting with a model $y=a^{*} \exp \left(b^{*} x\right)$ was used (we also tested a linear procedure and a power procedure which resulted in a worse fitting). The Mann-Whitney rank sum test was used to compare the scores on the Click Test (total number of clicks for the 3 test durations: 15,30 and $45 \mathrm{sec}$ ) between men and women for right-handed and left-handed subjects. The Student t-test was applied for ambidextrous subjects. The relationship between motor performance (total number of clicks) and age was assessed by applying a linear regression procedure $y=a * x+b$, with a maximum of 200 iterations, a step size of 1 and a tolerance fixed at $1 \mathrm{e}^{-10}$ (an exponential procedure and a power regression were applied but the $\mathrm{p}$ value was lower for the linear approach). The $95 \%$ confidence interval and the $95 \%$ prediction interval were estimated (a 
similar method was also applied for the the fitting procedures stated below)

We subsequently splitted the data in 3 age groups (young: 19-39 years, $\mathrm{n}=87$ subjects; middle age: 40-59 years, $n=81$ subjects; old: $60-89$ years, $n=84$ subjects). To compare the scores on the dominant side and the nondominant side for each test duration (15, 30 and $45 \mathrm{sec})$ within the 3 age groups, the Student t-test was used. To compare the symmetry index (performance on the dominant side divided by the performance on the non-dominant side) as a function of the test duration $(15,30$ and $45 \mathrm{sec})$ in the 3 age groups, the Friedman repeated measures analysis of variance on ranks was used. To compare the ratios 45-15 (ratios of the performance for $45 \mathrm{sec}$ divided by the performance for 15 seconds) between the dominant and the non-dominant hand, the Mann-Whitney rank sum test was used. In the 3 age groups, we assessed the relationship between test duration and motor performances using a linear regression procedure, both for the dominant and non-dominant side. In order to assess the age group effect, the gender effect and the interaction age group $\mathrm{x}$ gender effect, we performed a threeway analysis of variance (ANOVA) with age, gender and time duration side (T15Dom, T15NonDom, T30Dom, T30NonDom, T45Dom, T45NonDom) as independent variables. We applied the Scheffe test (more conservative than the Newman-Keuls procedure or the Duncan test) for posthoc comparisons. We used the Holm-Sidak test for the pairwise multiple comparison procedure. For the repeatability between 3 successive measurements on the same day (each side, 3 durations: 15, 30 and $45 \mathrm{sec}$ ), we computed the coefficients of variation (CV). For the intra-rater reliability (assessment on 4 consecutive days, each side and 3 durations) the intra-class coefficients were computed (ICC; ICC were interpreted as follows: $<0.40$ poor, $0.40-0.75$ fair to good, $>$ 0.75 excellent agreement [36]). For the correlation of the results obtained between the two observers (inter-rater), Pearson's product moment correlation was calculated. For the internal consistency, the Cronbach alpha coefficient was computed. For the relative performances, the correlation between the Click Test, the box-and-block test and the 9hole peg test was assessed. We applied a linear regression procedure (we also tested an exponential regression) and we estimated the $95 \%$ confidence interval and the $95 \%$ prediction interval.

\section{RESULTS}

No difference was found in terms of age between men (median: 49.50 years; 25\%: 32.0; 75\%: 65.25) and women (median: 49.94 years; 25\%: 30.0; 75\%: 67.75) (MannWhitney rank sum test: $\mathrm{p}=0.996)$. By contrast, handedness, as assessed by the Edinburgh inventory, was similar in men (median: -80; 25\%: -100; 75\%: -50) and women (median: 100; 25\%: $-100 ; 75 \%$ : -70) as shown by the Mann-Whitney rank sum test $(\mathrm{p}=0.164)$. The best fit between the mean age per decade and the mean corresponding score on the Cochin scale was obtained with an exponential curve (Fig. 2). For the subgroup of older subjects (age: 60-89 years), we found a significant negative linear correlation between the Cochin score and the performances (T15Dom: $y=56.26-1.04 * x, p=$ 0.0149; T15NonDom: $\mathrm{y}=50.93-1.21 * \mathrm{x}, \mathrm{p}=0.0034$; T30Dom: $\mathrm{y}=105.42-2.10 * \mathrm{x}, \mathrm{p}=0.0083$; T30NonDom: $\mathrm{y}=$ 95.69-2.423*x, $\mathrm{p}=0.0007$; T45Dom: $\mathrm{y}=150.45-3.18 * \mathrm{x}, \mathrm{p}=$ 0.0043; T45NonDom: $\mathrm{y}=135.65-3.43 * \mathrm{x}, \mathrm{p}=0.0005-$ corresponding graphs are shown in the supplementary file). The mean/median/SD/percentiles 25 and 75/mean +/- 2.5 SD values of the number of clicks are given in the supplementary table (values grouped for right-handed subjects, lefthanded subjects, ambidextrous subjects and also grouped for the 7 decades investigated). For the scores on the Click Test in right-handed subjects $(n=205)$, we found a gender effect using the Mann-Whitbney rank sum test $(n=82$ men versus $\mathrm{n}=123$ women: $\mathrm{p}<0.001$ for T15Dom; T15 Non Dom, T30 Dom, T30 NonDom, T45 Dom and T45 Non Dom $\mathrm{p}=$ 0.816). By contrast, we did not identify a gender effect for left-handed subjects ( 7 men versus 17 women; T15 Dom $\mathrm{p}=$ 0.338; T15 NonDom $\mathrm{p}=0.34$; T30 Dom $\mathrm{p}=0.408$; $\mathrm{T} 30$ Non Dom $\mathrm{p}=0.235$; $\mathrm{T} 45$ Dom $\mathrm{p}=0.849 ; \mathrm{T} 45$ NonDom $\mathrm{t}$ test $\mathrm{p}=$ 0.266). For ambidextrous subjects (12 men versus 11 women) we found a gender effect for T15 Dom $(\mathrm{p}=0.018)$, T15 Non Dom $(p=0.006)$ and T45 Dom $(p=0.031)$. No gender effect was identified for T30 Dom $(p=0.138)$, T30 Non Dom $(p=0.183)$ and T45 Non Dom $(p=0.197)$.

\section{Relationship between Age and Cochin score}

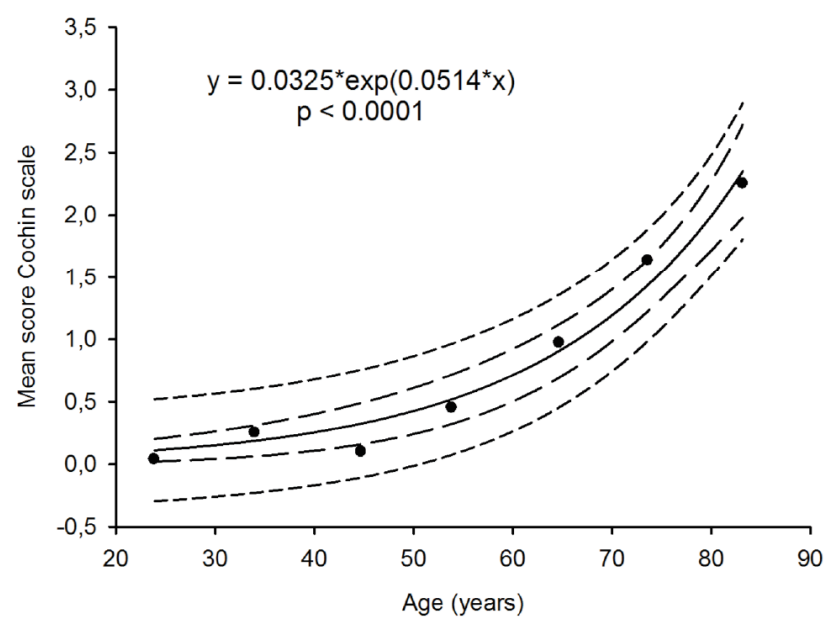

Fig. (2). Relationship between age and Cochin score. Exponential fitting of the relationship between mean age per decade (expressed in years) and the mean score of the Cochin scale. Fitting with a model $y=a^{*} \exp \left(b^{*} x\right)$. Each dot corresponds to the mean value for each decade. $95 \%$ confidence bands (long dash) and $95 \%$ prediction bands (short dash) are shown. $\mathrm{N}=252$ subjects.

Fig. (3) illustrates the motor performances obtained as a function of the age for the whole group of subjects $(n=252)$ and the side investigated (dominant and non-dominant). We found that motor performances decreased significantly in a linear fashion as a function of the age for both the dominant side and the non-dominant side $(\mathrm{p}<0.0001$ for 15,30 and 45 sec in the 2 upper limbs).

In the whole group of subjects, for both the dominant and non-dominant side, a highly significant linear relation for motor performance was found as a function of the test duration, with a positive slope of the regression line of 3.71 on the dominant side and 3.31 on the non-dominant side 
Dominant

A

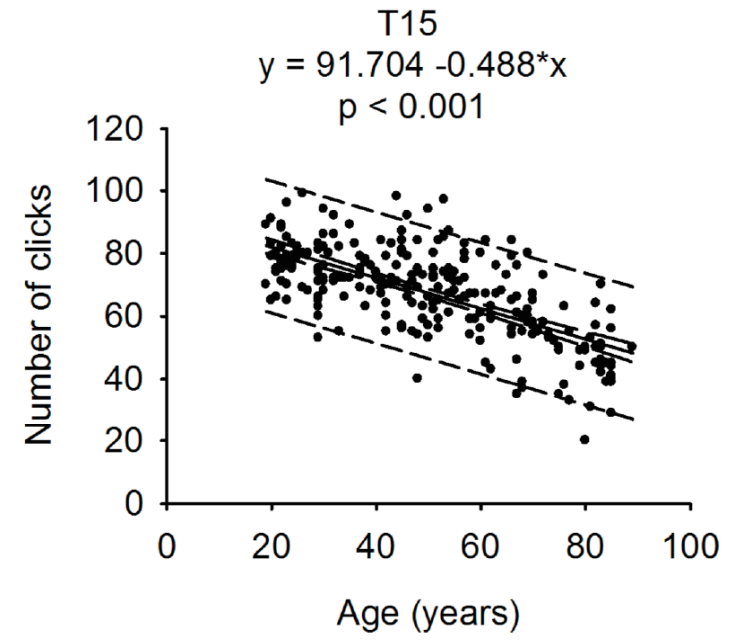

B

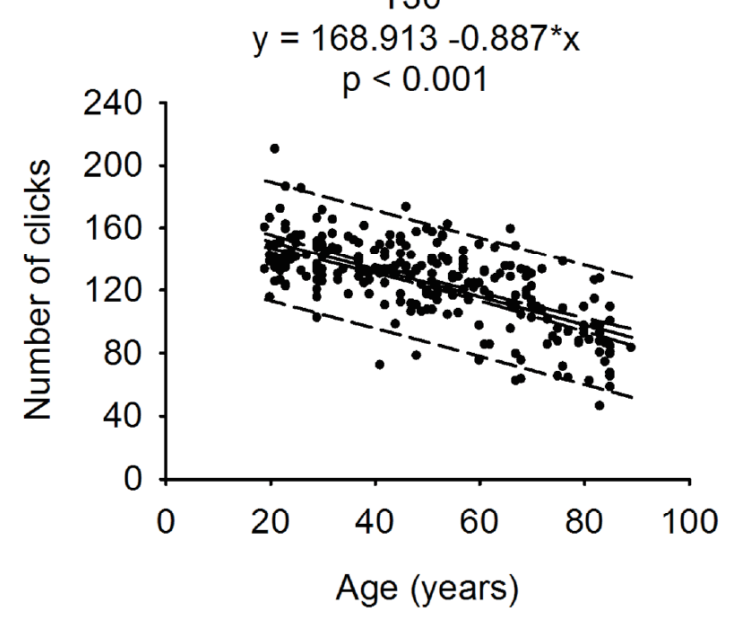

C

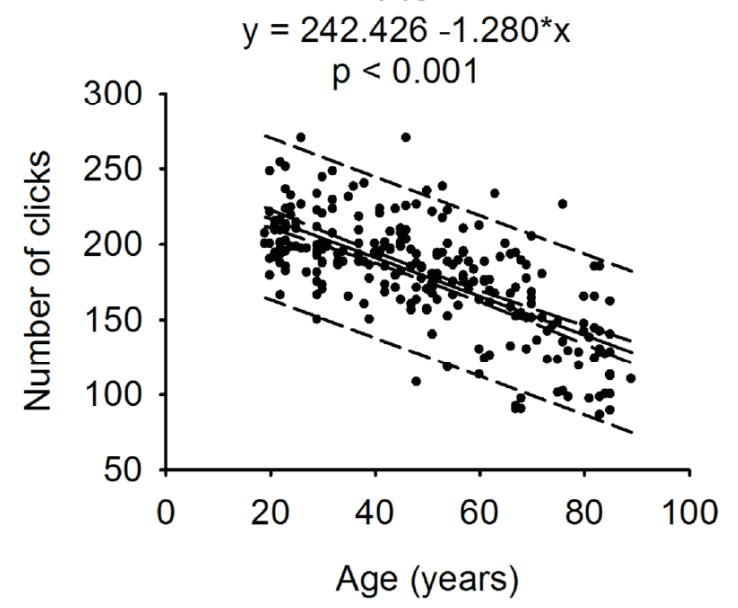

Non Dominant
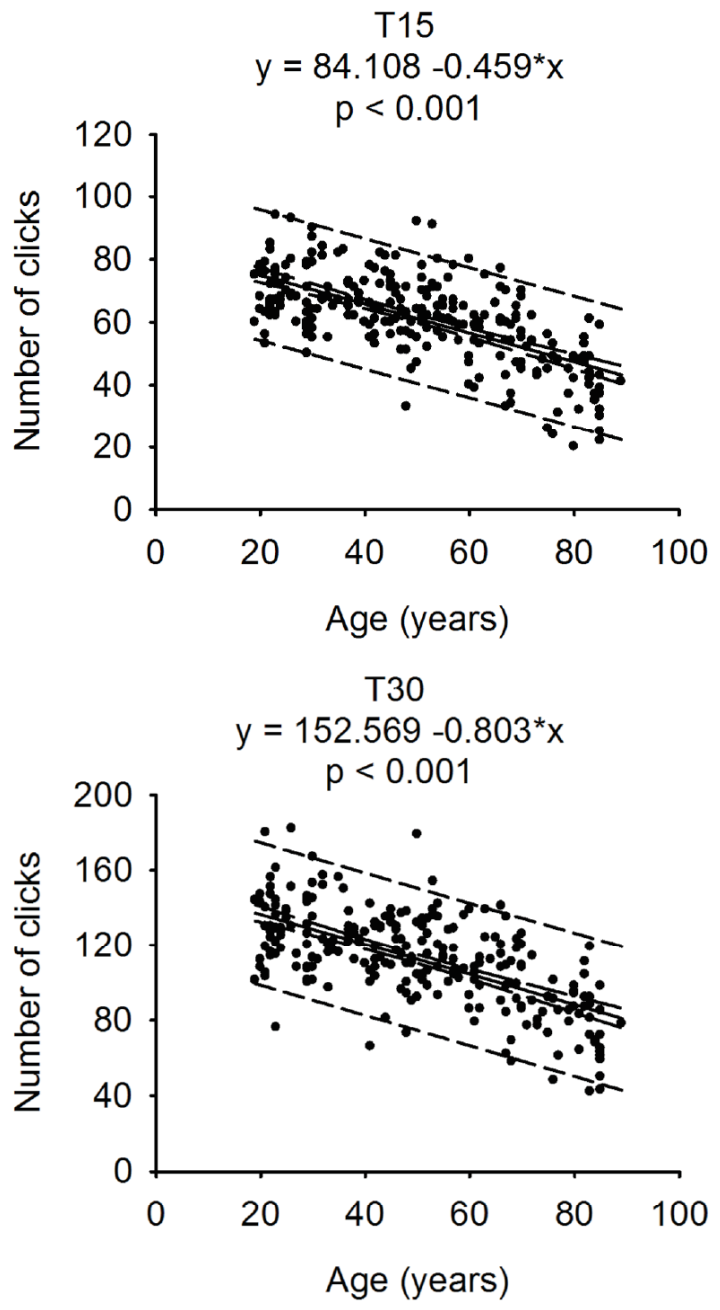

T45

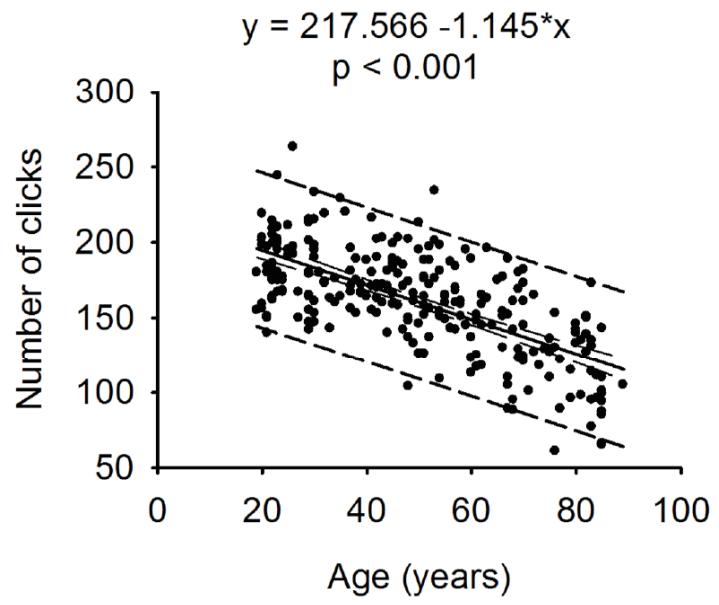

Fig. (3). Performances (number of clicks) as a function of the age of subjects for each upper limb (left panels: dominant side; right panels: non-dominant side). A: test duration of $15 \mathrm{sec}$ (T15); B: $30 \mathrm{sec}$ (T30); C: $45 \mathrm{sec}$ (T45). Regression lines, 95\% confidence bands (long dash) and $95 \%$ prediction bands (short dash) are shown. $\mathrm{N}=252$ subjects.

$(p<0.0001$ for both sides). The results of the linear regression fitting are illustrated in Fig. (4) for the 3 age groups and each side. A highly significant relationship was found for the 3 age groups $(\mathrm{p}<0.0001)$, but the $\mathrm{R}^{2}$ values were lower in the older group.
For the 3 age groups, scores for the dominant side were significantly higher as compared to the non-dominant side for $15 \mathrm{sec}, 30 \mathrm{sec}$ and $45 \mathrm{sec}$ (Fig. (5); p $<0.001$ in the young age group and the middle age group; old age group: $\mathrm{p}$ $=0.006$ for $\mathrm{T} 15, \mathrm{p}=0.005$ for $\mathrm{T} 30, \mathrm{P}=0.003$ for $\mathrm{T} 45$ ). 
A.Dominant

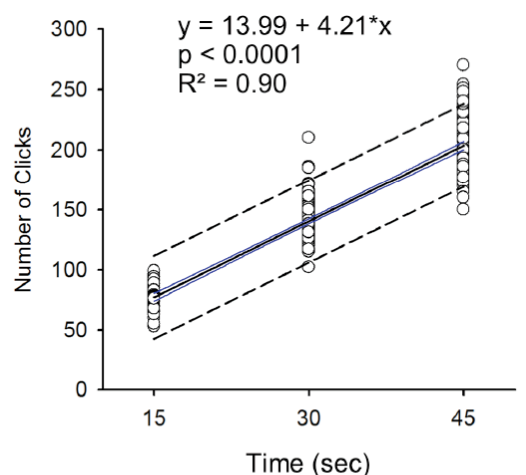

B.Non Dominant

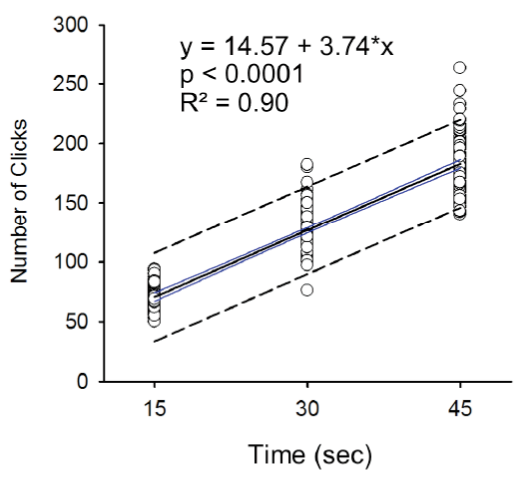

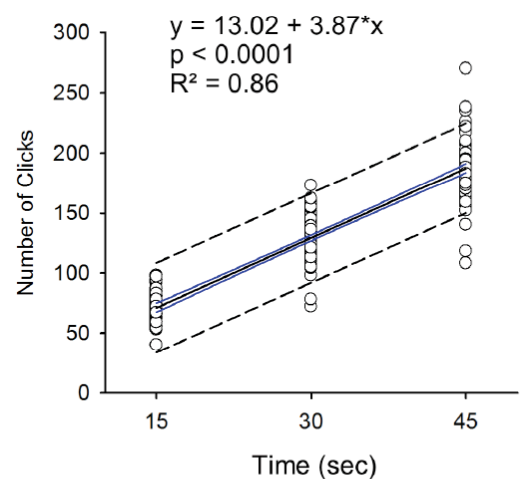
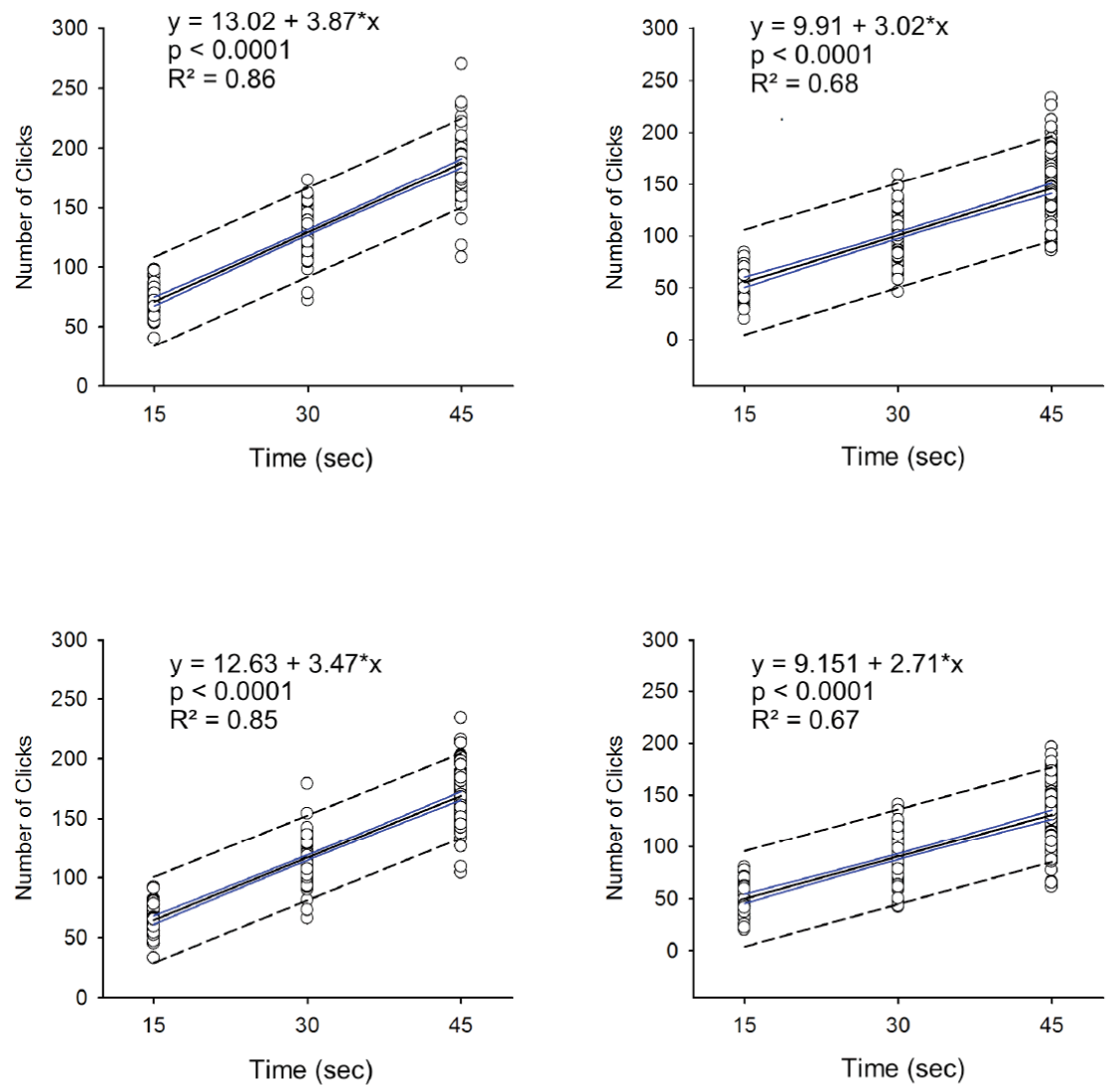

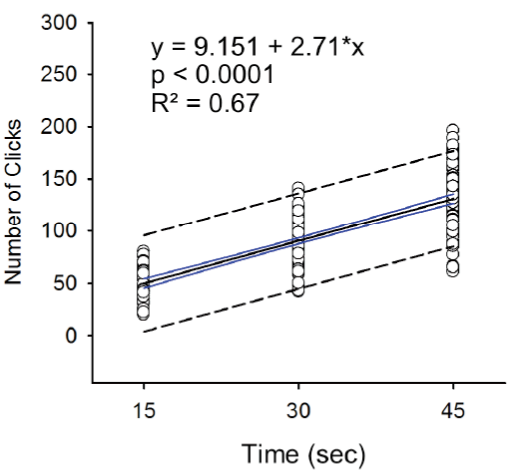

Fig. (4). Number of clicks (performances) as a function of test duration in the 3 age groups. A: dominant side. B: non-dominant side. Regression lines, 95\% confidence bands (blue lines) and 95\% prediction bands (dashed lines) are shown. $\mathrm{N}=87, \mathrm{n}=81$ and $\mathrm{n}=84$ subjects, respectively.

For the whole group of subjects, the values of the symmetry index (ratio of the scores of the dominant/scores on the non-dominant side) were similar for T15, T30 and T45 $\sec (p=0.623$; by contrast, the symmetry index was higher for $45 \mathrm{sec}$ as compared to $15 \mathrm{sec}$ for the CAM test [8]). Moreover, unlike for the CAM test (this test is characterized by ratios $45 / 15$ significantly higher on the dominant side as compared to the non-dominant side), we found no statistically significant difference $(\mathrm{p}=0.171)$ for the ratios $45 / 15$ between the dominant side (mean +/- SD: 2.68 +/- 0.404; median: 2.66, 25\%: $2.47,75 \%: 2.85$ ) and the non-dominant side (mean +/- SD: 2.65 +/ 0.397; median: 2.63, 25\%: 2.49 , 75\%: 2.78) for the Click Test. Similar observations were made considering the 3 age groups.

A significant age group effect was found $(\mathrm{F}(2,1476)=$ 503.46; $\mathrm{p}<0.00001$; Scheffe post-Hoc test: $\mathrm{p}<0.00001$ ), as well as a significant gender effect (performances in females lower than the performances in males; F $(1,1476)=155.47$; $\mathrm{p}<0.001$; Scheffe post-hoc test: $\mathrm{p}<0.001)$. We also found a significant interaction age group $\mathrm{x}$ gender $(\mathrm{F}(2,1476)=$ $6.74 ; p=0.0012)$. For all the time durations $(15,30$ and 45 sec) and for both sides (dominant and dominant), the HolmSidak post-hoc test demonstrated that performances were significantly better $(p<0.00001)$ in the young age group than in the middle age group, and in the middle age group than in the old age group $(\mathrm{P}<0.00001)$. Performances were significantly better in males as compared to females in the young age group $(\mathrm{p}<0.0001)$ and in the middle age group $(\mathrm{p}<0.0001)$, whatever the test duration and the side tested. By contrast, for the old age group, the performances were better in males as compared to females only for T30Dom and T45NonDom. Considering the group of females for T15Dom, performances were not better $(\mathrm{p}=0.23)$ in young age group as compared to middle age group, but better $(\mathrm{p}<0.05)$ in the middle age group as compared to old age group for the 3 time durations and both sides. For males, similar observations were made $(\mathrm{p}<0.05)$ using the pairwise multiple comparison procedure, with the exception of T15Dom (performances similar in the young age group and in the middle age group).

For the repeatability, the CVs were $4.21 \%$ (T15), $4.18 \%$ (T30), 3.20\% (T45) for the dominant hand and $4.47 \%$ (T15), $4.21 \%$ (T30), 4.04\% (T45) for the non-dominant hand. The intra-rater reliability was excellent as confirmed by the ICC. On the dominant side, the ICC was $0.89,0.97$ and 0.98 , respectively for 15,30 and $45 \mathrm{sec}$. On the non-dominant side, the ICC was $0.91,0.97$, and 0.96 for $15 \mathrm{sec}$, for $30 \mathrm{sec}$ and for $45 \mathrm{sec}$. The mean responsiveness was 0.22 (range: 0.14 to 
19-39 Years
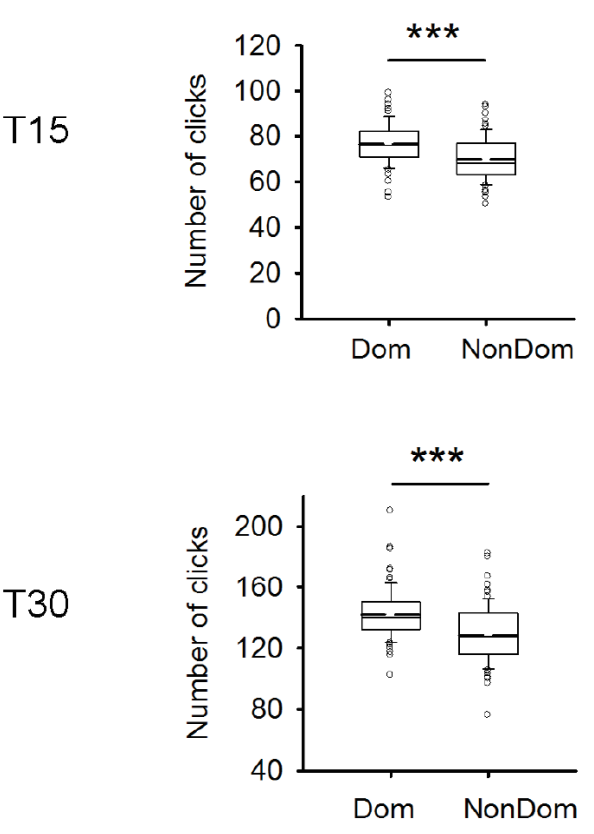

T30

$\mathrm{T} 15$
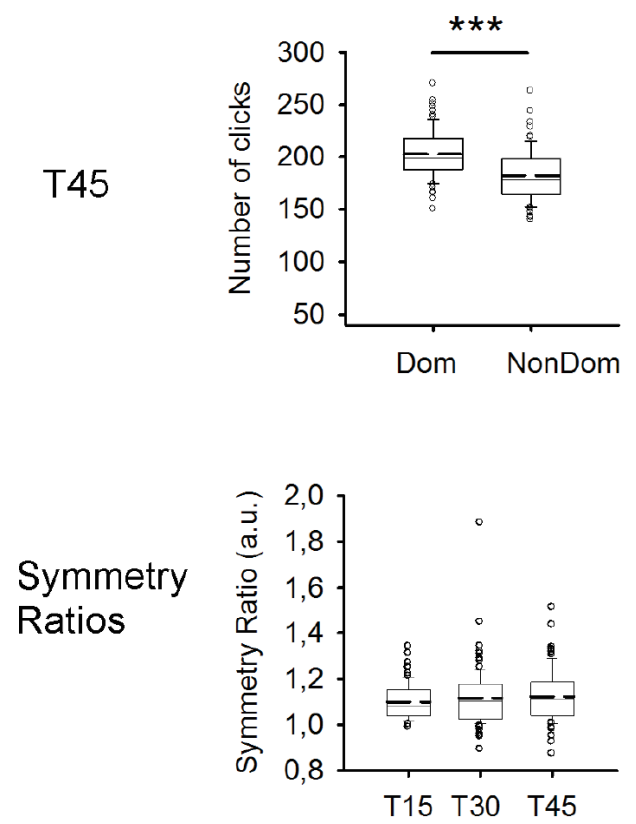

40-59 Years
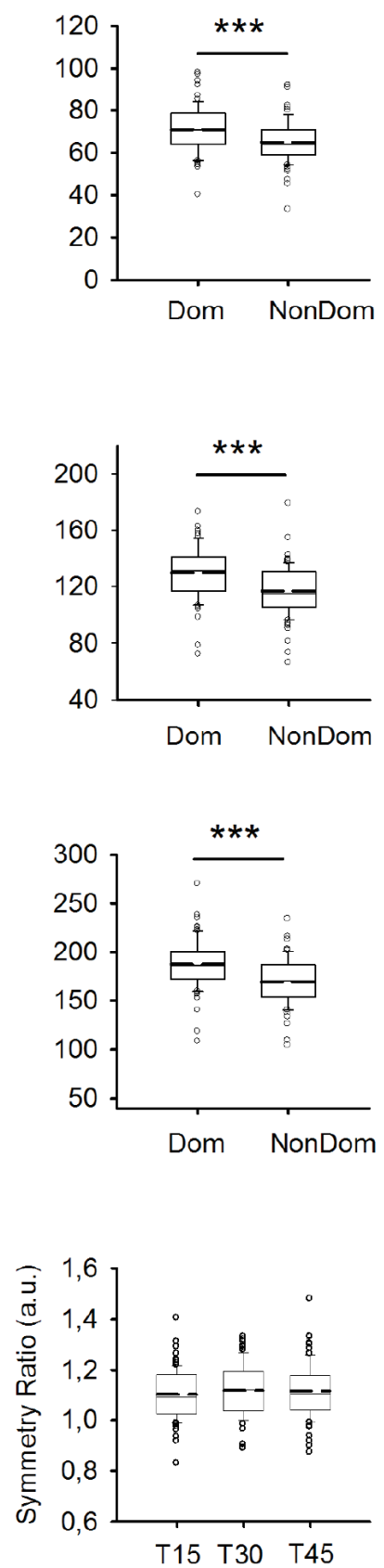

60-89 Years
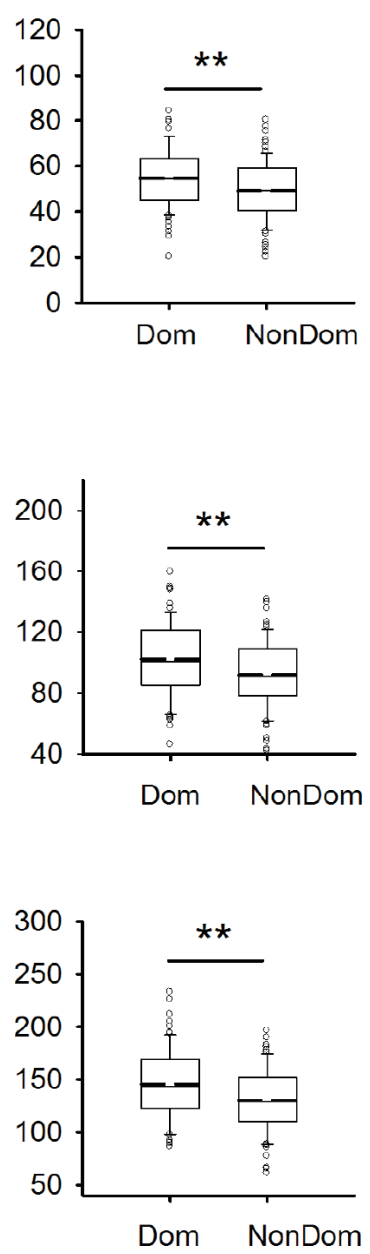

Fig. (5). Differences between the performances (number of clicks) on each side in the 3 age groups. T15: duration of 15 seconds (T15Dom: dominant side; T15NonDom: non-dominant side); T30: 30 seconds (T30Dom: dominant side; T30NonDom: non-dominant side); T45: 45 seconds (T45Dom: dominant side; T45NonDom: non-dominant side). Symmetry ratios are illustrated in the bottom panels (ratios of number of clicks on the dominant side divided by number of clicks of the non-dominant side) for $15 \mathrm{sec}$ (T15), $30 \mathrm{sec}$ (T30) and 45 sec (T45). Median values (continuous lines), means (dashed lines) and outliers are shown. ***: $\mathrm{p}<0.001, * *: \mathrm{p}<0.01 . \mathrm{N}=87, \mathrm{n}=81$ and $\mathrm{n}=84$ subjects, respectively.

0.33). For the dominant side, Pearson's product moment correlation (inter-rater assessment) was 0.90 (T15, $\mathrm{p}=0.0003), \quad 0.96 \quad(\mathrm{~T} 30, \mathrm{p}<0.0001)$ and $0.79 \quad(45 \mathrm{sec}$, $\mathrm{p}=0.0070)$. On the non-dominant side, the Pearson's product moment correlation was 0.85 (15 sec, $\mathrm{p}=0.0019), 0.93$ (30 sec, $\mathrm{p}<0.0001)$ and $0.91(45 \mathrm{sec}, \mathrm{p}=0.0002)$. For the internal consistency, the Cronbach alpha coefficient was 0.95 . The relative performances of the Click Test with scores on the box and block test and the 9-hole peg test was very high. Fig. (6) illustrates the positive linear correlation between the box and block test and the Click Test $(\mathrm{p}<0.0001)$. Fig. (7) shows the negative linear correlation between 9-hole peg test and the Click Test $(\mathrm{p}<0.0001)$. 


\section{RIGHT SIDE}

A

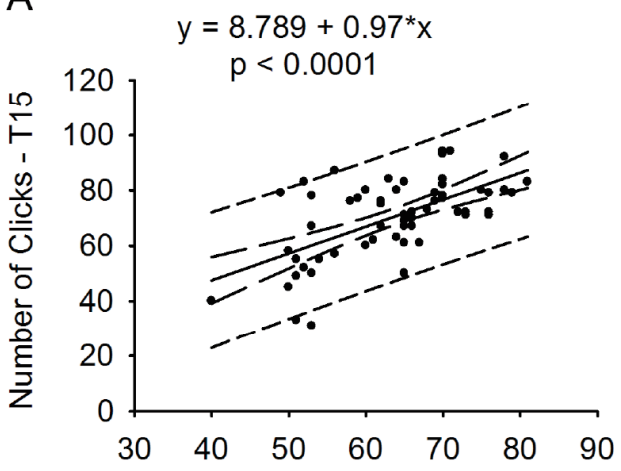

Score BBT

B

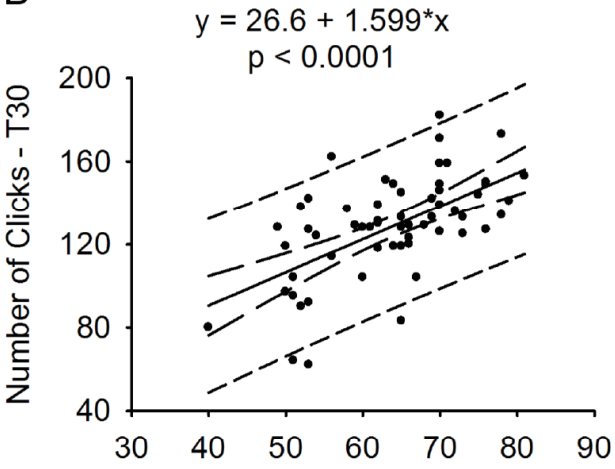

Score BBT

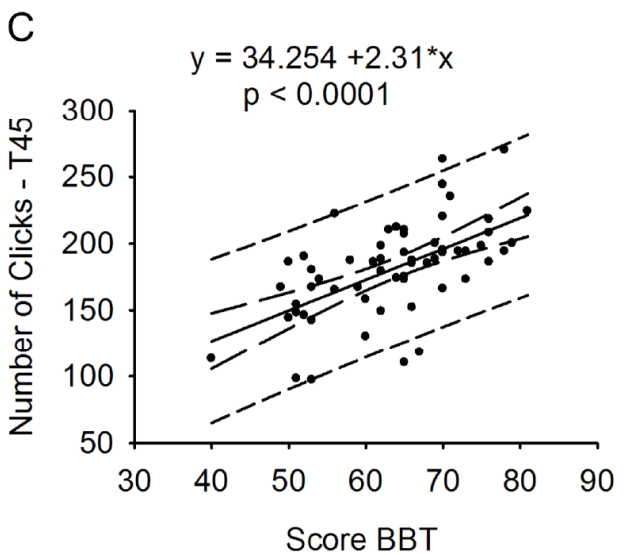

\section{LEFT SIDE}
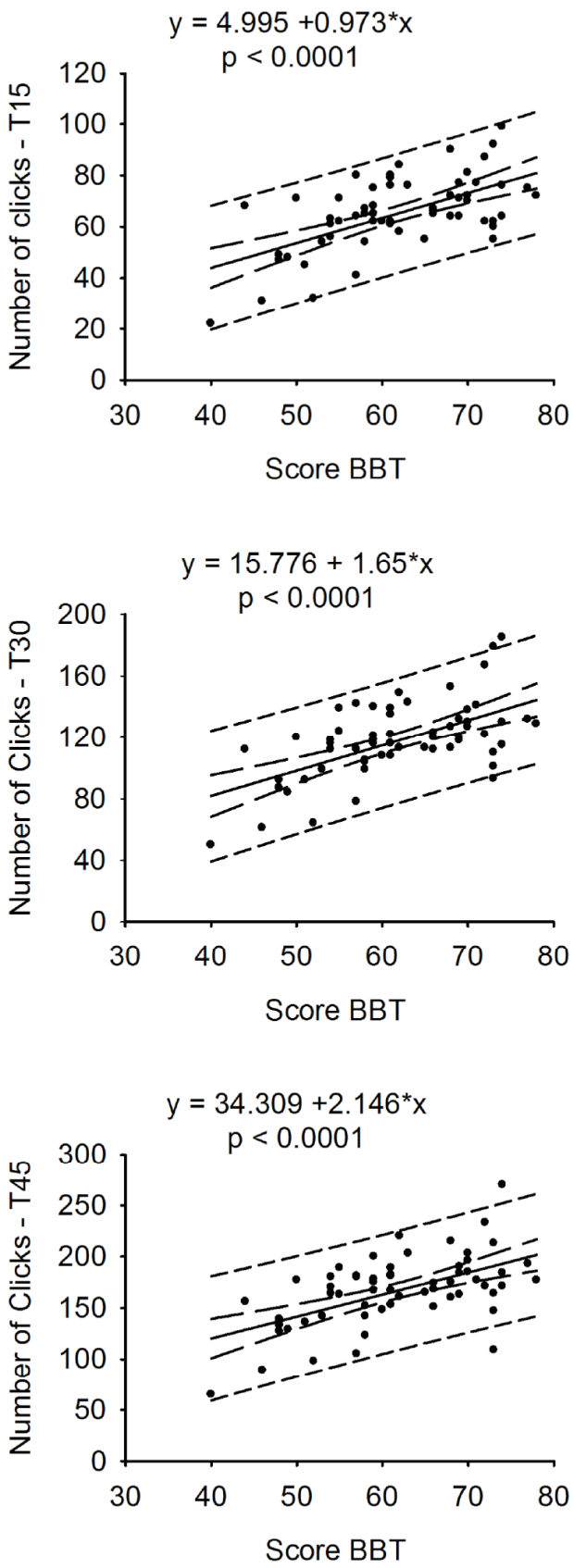

Fig. (6). Relationship between the score of the box and block test (BBT) and the number of clicks. Left panels: tasks performed on the right side. Right panels: tasks performed on the left side. A: T15 corresponds to $15 \mathrm{sec}$; B: T30 corresponds to 30 sec; C: T45 corresponds to 45 sec. Regression lines, 95\% confidence bands (long dash) and 95\% prediction bands (short dash) are shown. $\mathrm{N}=60$ subjects (52 right-handed, 8 left-handed).

The activation of the brain motor network during the Click Test is illustrated in the supplementary file.

\section{DISCUSSION}

The Click Test stands for a novel procedure to assess repeated elementary motor sequences of the thumb. The major findings of this exploratory study with the Click Test in a cohort of 252 healthy subjects can be summarized as fol- lows. First, a highly significant linear correlation was found between motor performance (number of clicks) and the duration of the test. Second, as reflected by a decline of the results in the elderly, age significantly influenced test performances. Third, subjects performed significantly better on the Click Test using the dominant hand, which indicates that the Click Test is sensitive to handedness. These three findings were comparable to the findings of the CAM test reported earlier [8]. However, in contrast to the CAM test, the sym- 


\section{RIGHT SIDE}
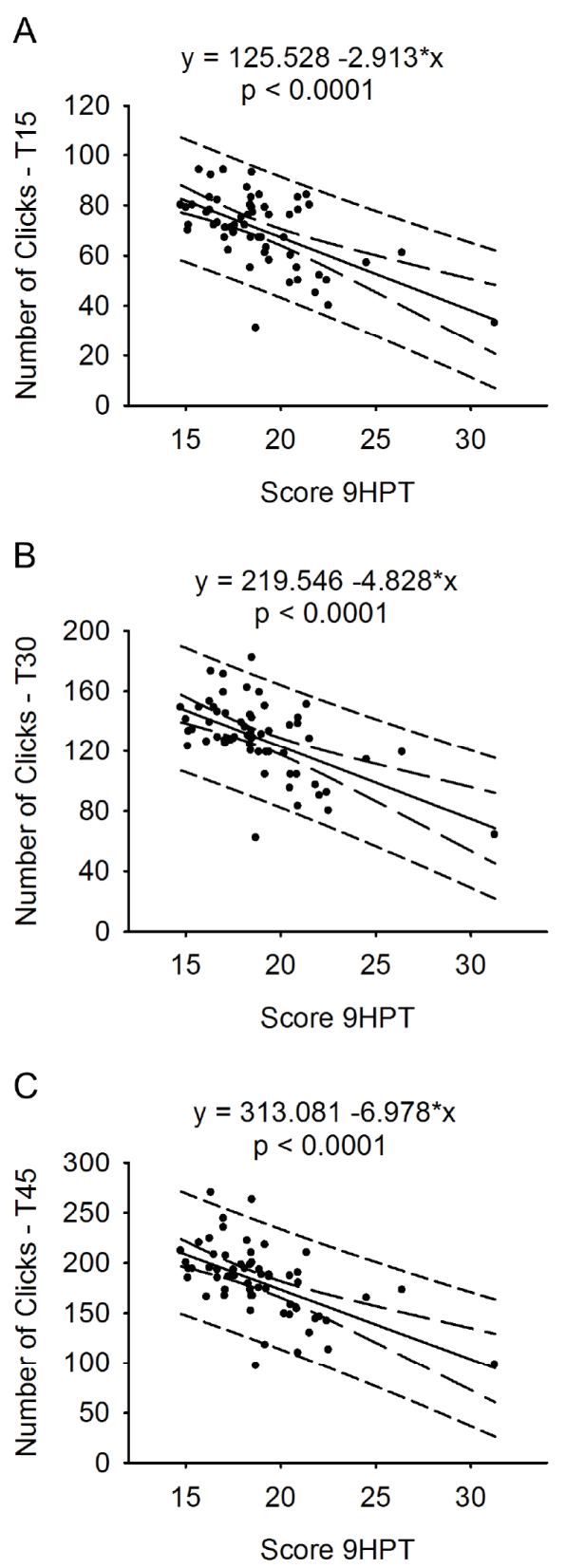

\section{LEFT SIDE}
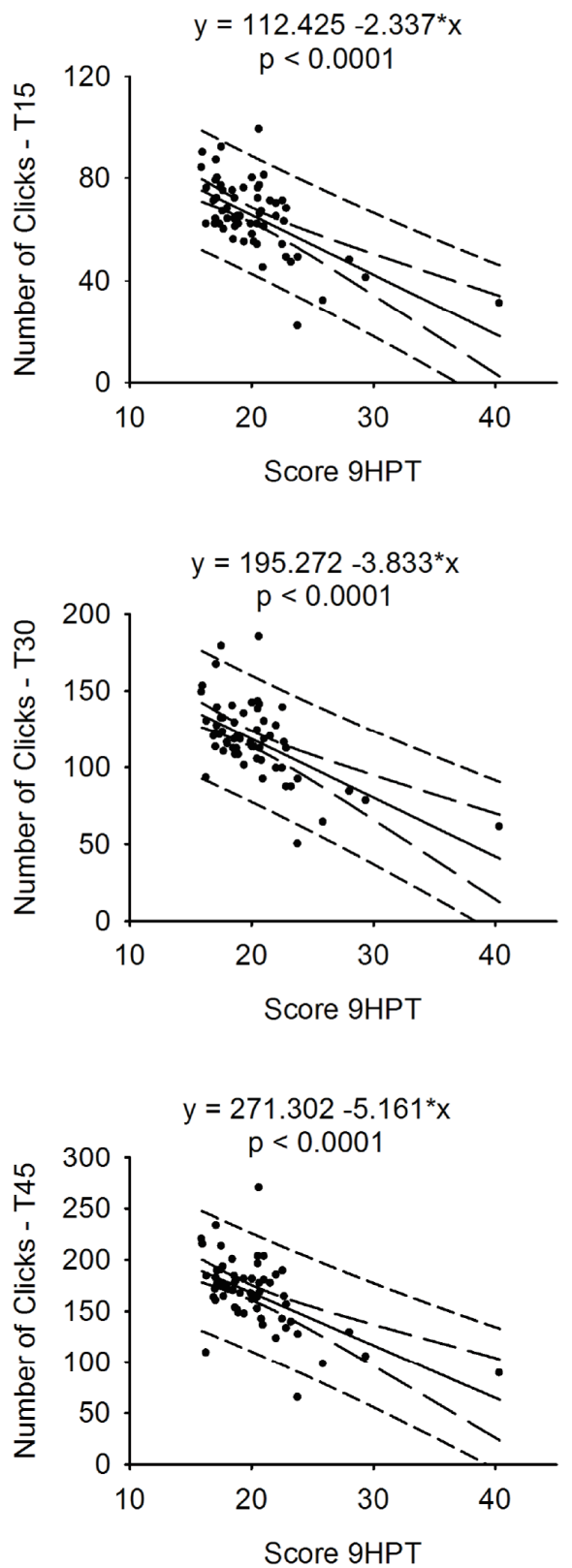

Fig. (7). Relationship between the score of the 9-hole peg test (9HPT) and the number of clicks. Left panels: tasks performed on the right side. Right panels: tasks performed on the left side. A: T15 corresponds to $15 \mathrm{sec}$; B: T30 corresponds to 30 sec; C: T45 corresponds to 45 sec. Regression lines, 95\% confidence bands (long dash) and 95\% prediction bands (short dash) are shown. $\mathrm{N}=60$ subjects (52 right-handed, 8 left-handed).

metry index for the Click Test is independent of the test duration and the $45 / 15$ ratios are similar on the dominant and non-dominant side, indicating that the $45 / 15$ ratios are not influenced by handedness for the Click Test. This test has a high internal consistency, and shows similar performances as compared to widely used tests. Indeed, the performances on the Click Test highly correlated with the scores obtained with the box and block test (positive correlation) and the 9hole peg test (negative correlation), two tools widely disseminated in the clinic for the quantification of upper limb performances, especially in the rehabilitation and follow-up of chronic neurological disorders such as multiple sclerosis
[37]. We found that the number of clicks increased linearly as a function of task duration. This observation is not surprising, due to the selection of the durations (15, 30 and 45 sec) to complete the task, below the threshold (about $50 \mathrm{sec}$ ) associated with a fatigue-induced decline of performances. Therefore, the durations of 15,30 and 45 sec appear very well suited to establish normative data, taking into account earlier findings from the horizontal pointing test and the CAM test $[8,28]$.

Our convenience sample was not equal in the distribution of the different age groups or between men and women. In- 
deed, we have applied a list of exclusion criteria in a strict way. Many studies only mention that subjects included have "no restriction of daily life activity". We know from the ground that this is not enough, but this renders the recruitment much more difficult. In particular, it is very difficult to identify elderly patients without comorbidities.

The performance was better in men as compared to women. Such gender effect is known for other tests of hand function. For instance, men perform significantly better than women for hand grip strength and key pinch strength between the thumb and the index [38]. Mean grip strength is about $40 \%$ less in women than in men [39]. In some studies, female grip strength was $60 \%$ to $70 \%$ less than male grip strength, without difference between dominant and nondominant hands [40]. Strong age and gender effects have been reported for dexterous manipulation with fingertips, for instance for the strength-dexterity test involving the pulps of the thumb and the index [41]. There is little debate regarding the gender effect upon muscle strength, but the effects of gender on hand motor skills are relatively less documented, despite experimental evidence of differences in finger coordination strategies for more than 30 years [42]. The mechanisms of gender effect for finger motor tasks remain to be established. Several possibilities have been raised, in particular sex differences in the excitability of motoneuron pools, roles of hormones on the sensorimotor system, differences in brain connectivity in sensorimotor areas between perception and coordinated action $[41,43]$. Connectivity in male brains facilitate intra-hemispheric exchange of information, whereas female brains allow a better inter-hemispheric communication [43].

The relevance of the regression formulas between age and scores during the Click Test is that the performance can be anticipated by inserting the age in the equation. This might be particularly useful for clinicians during the monitoring of patients included in a rehabilitation program, for sport sciences in general, for the estimation of neuromuscular functions in older adults and after surgery of the upper limb. The performances during the Click Test might used as a surrogate parameter to estimate physical fitness and could aid to detect frailty in the elderly. Indeed, the older population is more vulnerable to physical deconditioning following illness, with a higher risk of immobility and dependency.

To our knowledge, this is the first study showing that scores on the Cochin scale increase exponentially with normal ageing. Considering the items of the scale, changes in hand movements linked to ageing might be affected as a result of difficulties in executive abilities [44]. For instance, the manipulation of objects during daily life is impaired with increasing age [45]. The decline of motor performances with age fits with the general observation that slowness of movements is a major feature of goal-directed movements in older adults [46]. Both biomechanical changes in limb muscles and the age-related alteration of proprioception, position sense and tactile sense likely contribute to decreased performances [12-18]. The process of motor sequencing itself is affected in the elderly. For instance, in a group of 76 healthy participants aged between 18 and 93 years, a slowing of movements was identified for complex sequences involving finger movements [47]. Motor and cognitive sequencing is also typically affected in neurological disorders such as Parkinson's disease or cerebellar disorders [48]. Elderly subjects develop a slow and insidious loss of muscle mass, attributed to the complex interactions between impairments of the neuromuscular junction and proteins turn-over, changes in the endocrine system as well as modifications in behavior itself [49]. Furthermore, in terms of biomechanical aspects, older healthy subjects develop an abnormal curvature of both the trapezial and metacarpal saddles as demonstrated by $3 \mathrm{D}$ bone models reconstructed from CT scans of the hand [50].

The Click Test is an easy to understand (none of our subjects failed to understand the task instructions) and low cost ( $<10$ euros) tool to quantify the motor performances during successive flexions/extensions of the thumb. This test might complement the standardized tests currently used to evaluate upper limb performances, such as the box and block test or the 9-hole peg test $[24,29,51]$. In terms of motor control, the box and block test requires a grasping movement and the upper limb trajectory has a strong component in the horizontal axis with a rotation of the head. For the 9-hole peg test the dowels need to be picked up with the fingers (pinch task) and moved to a hole with dexterity, with a limited movement of the shoulder. The Click test is more restricted to the thumb itself and, as a novel tool for the quantification of fast motor sequencing distally, adds to current assessments.

The Click Test might be used in selected patient populations with the aims of evaluating its potential for (a) identification of markers of disease onset; (b) monitoring disease progression; and (c) assessing the effects of therapies. In particular, the Click Test might be applied as a novel outcome tool of motor function in stroke (territory of the middle cerebral artery, brainstem stroke, stroke of the spinal cord), multiple sclerosis, myasthenia (patients are highly sensitive to motor fatigue). Table 2 lists potential clinical applications of the Click Test in selected populations of patients.

The motor network which is activated during the Click Test involves the sensorimotor cortex, the supplementary area (SMA) and the lobules V-VI of the cerebellum as well as the vermis (this is illustrated in the supplementary file for one right-handed subject performing fast flexions/extensions of the thumb). The asymmetry in activation patterns related to handedness is explained by an ipsilateral deactivation of the sensorimotor cortex for the dominant hand as a result of transcallosal inhibition [52]. However, fMRI studies with a sufficient number of young and old participants should be performed before drawing conclusions. The Click Test might also be used in the context of the many rheumatologic diseases affecting the thumb. Indeed, the 3 joints of the thumb (carpometacarpal joint, metacarpophalangeal joint, interphalangeal joint) are commonly affected by arthrosis and arthritis, with a considerable clinical burden in advanced cases due to joint failure [53-55]. Rhizarthosis is a very common degenerative joint disorder, causing pain, with functional impacts and often prompting speciality care, including surgery such as arthrodesis [56]. Prevalence of radiographic involvement is very high, with values up to $35.8 \%$ in the general population aged $>55$ years [1]. Moreover, the incidence of rheumatoid arthritis, a frequent cause of arthritis of thumb joints, is expected to increase in the next 10 years as a result of the increasing proportion of elderly people [57]. The Click 
Table 2. Prospects for future clinical applications of the Click Test.

\begin{tabular}{|c|c|}
\hline Field & Applications \\
\hline Neurological Disorders & $\begin{array}{l}\text { Central Nervous System } \\
\text { Monitoring of therapies in Parkinson's disease (bradykinesia). } \\
\text { Follow-up of stroke causing motor deficits of thumb movements. } \\
\text { Follow-up of cerebellar ataxias (clumsiness, deficits in sequencing). } \\
\text { Follow-up of multiple sclerosis (paresis, clumsiness). } \\
\text { Quantification of thumb performances in spinal cord lesions (tetraplegia). } \\
\text { Functional evaluation of Amyotrophic Lateral Sclerosis (ALS). } \\
\text { Implementation within the field of Brain-Computer Interfaces (BCIs) to monitor the effects of brain stimulation. } \\
\text { Peripheral Nervous System } \\
\text { Monitoring of brachial plexus injury. } \\
\text { Follow-up of peripheral motor neuropathies (Guillain-Barré syndrome). } \\
\text { Follow-up of myasthenia. }\end{array}$ \\
\hline Rheumatology & $\begin{array}{l}\text { Follow-up of therapies of rhizarthrosis, rheumatoid arthritis. } \\
\text { Functional evaluation of calcinosis of the thumb (systemic sclerosis). } \\
\text { Quantification of effectiveness of home-based rehabilitation of the hand. } \\
\text { Assessment of rehabilitation of tendinosis associated with overuse of hand held devices (mobile phones, game con- } \\
\text { trols,...). }\end{array}$ \\
\hline Orthopedic Surgery & $\begin{array}{l}\text { Follow-up of reconstruction of the thumb. } \\
\text { Follow-up of carpometacarpal joint replacements. } \\
\text { Follow-up of decompressive surgery of carpal tunnel syndrome. } \\
\text { Follow-up of surgery of ligamentous injuries to the thumb. } \\
\text { Follow-up of traumatic thumb during rehabilitation. }\end{array}$ \\
\hline
\end{tabular}

Test might be easily implemented in the clinical setting to monitor or compare thumb carpometacarpal joint replacements [58]. The Click Test might also be used to evaluate entrapment neuropathies of the median nerve (carpal tunnel syndrome) or the ulnar nerve (ulnar tunnel syndrome), or for the monitoring of brachial plexopathy as a clinimetric instrument. This condition may affect the control of the 4 extrinsic muscles (flexor pollicis longus, abductor pollicis longus, extensor pollicis longus, extensor pollicis brevis) and the 5 intrinsic muscles (muscles of the thenar eminence: abductor pollicis brevis, flexor pollicis brevis and opponens pollicis; adductor pollicis and first dorsal interosseous muscle) of the thumb. The flexor pollicis brevis and longus (these muscles are innervated by the median nerve and the ulnar nerve) are the prime movers for the flexion of the thumb during the Click Test, whereas the extensor pollicis brevis and the extensor pollicis longus (these muscles are innervated by the radial nerve) control the extension of the thumb. Another potential application relates to hand injuries which represent about $15 \%$ of sports injuries, including ligamentous injuries to the thumb [59]. Because athletes have high expectations for recovery, tools assessing specific thumb movements would be very valuable in the diagnostic intervention and treatment. In terms of relevance for activi- ties of daily life, the-increasingly-intensive use of hand held devices causes tendinosis of extensor pollicis longus and myofascial pain syndrome involving the 1st interossei, thenar muscles and extensor digitorum communis [2]. Tendon rupture has even been reported [60]. The tendon of the flexor pollicis longus and the median nerves are vulnerable to the overuse of smartphones, especially on the dominant side [61]. Children, adolescents and young adult now spend up to several hours every day typing text messages into their cell phones, answering email with their smartphone, and scrolling repeatedly through music lists. This is a source of repetitive stress injuries. This is another group of disorders for which the Click Test might be useful during follow-up. The performances in people performing repetitive motor tasks involving the thumb could be assessed prospectively outside the clinic, without need for bulky or expensive equipments.

The current version of the Click Test provides a global estimation of the total number of clicks over a given period of time (value of motor performance) but does not provide the details of the motor performances between the successive clicks throughout the task (the dynamic profile of performances is missing). A computerized version providing the timing between 2 successive clicks would be of added value 
(an eClick Test is under development: see also the supplementary file). This electronic version might also allow for (a) computing a parameter of the inter-clicks variability for successive movements; (b) estimation of the time spent for the flexion movement itself (movement time for flexion), the extension movement (movement time for extension) and the dwell time on the counter; and (c) extraction of the reaction time which is sensitive to ageing [62]. In combination with surface electromyography (EMG) recordings, a quantification of muscle contractions will allow to extract patterns of agonist-antagonist EMG discharges. We expect that the analysis of the reaction times along with the assessment of the EMG patterns will allow to distinguish between the executive functions and the orthopedic insufficiencies over the ages. Such a distinction cannot be made with the current version. Furthermore, it would be particularly interesting to investigate the activation of the motor cortex in a subgroup of elderly subjects. Indeed, ageing impacts also on the motor cortex itself, causing in particular cortical atrophy, impaired excitability and plasticity [63].

\section{ETHICS APPROVAL AND CONSENT TO PARTICI- PATE}

Not applicable.

\section{HUMAN AND ANIMAL RIGHTS}

No Animals/Humans were used for studies that are base of this research.

\section{CONSENT FOR PUBLICATION}

Not applicable.

\section{CONFLICT OF INTEREST}

The authors confirm that this article content has no conflict of interest.

\section{ACKNOWLEDGEMENTS}

FB is funded by the Faculty of Medicine, ULB. MM is supported by the FNRS Belgium and the Fonds Erasme.

\section{REFERENCES}

[1] Dahaghin S, Bierma-Zeinstra SMA, Ginai AZ, Pols HAP, Hazes JMW, Koes BW. Prevalence and pattern of radiographic hand osteoarthritis and association with pain and disability (the Rotterdam study). Ann Rheum Dis 2005; 64: 682-75.

[2] Sharan D, Mohandoss M, Ranganathan R, Jose J. Musculoskeletal disorders of the upper extremities due to extensive usage of hand held devices. Ann Occup Environ Med 2014; 26: 22.

[3] Reitan RM, Wolfson D. The halstead-reitan neuropsychological test battery: Theory and clinical interpretation. Tucson, AZ: Neuropsychology Press, 1985.

[4] Gauhar R, Wilkinson J, Harris J, Manning J, Herrick AL. Calcinosis preferentially affects the thumb compared to other fingers in patients with systemic sclerosis. Scand J Rheumatol 2016; 45: 317-20.

[5] Penfield W, Rasmussen T. The cerebral cortex of man: a clinical study of localization of function. New York, NY: Macmillan, 1950.

[6] Terao Y, Hayashi H, Kanda T, Tanabe H. Discrete cortical infarction with prominent impairment of thumb flexion. Stroke 1993; 24: 2118-20.
Asanuma H, Rosén I. Topographical organization of cortical efferent zones projecting to distal forelimb muscles in the monkey. Exp Brain Res 1972; 14: 243-56.

[8] Ansay C, Manto M, Camut S, et al. The CAM test: A novel tool to quantify the decline in vertical upper limb pointing movements with ageing. Aging Clin Exp Res 2016; 28: 221-30.

[9] Rand MK, Stelmach GE. Effects of hand termination and accuracy requirements on eye-hand coordination in older adults. Behav Brain Res 2011; 219: 39-46.

[10] Rand MK, Stelmach GE. Effect of aging on coordinated eye and hand movements with two-segment sequence. Motor Control 2012; 16: 447-65.

[11] Seidler RD, Alberts JL, Stelmach GE. Changes in multi-joint performance with age. Motor Control 2002; 6: 19-31.

[12] Cole KJ, Rotella DL, Harper JG. Mechanisms for age-related changes of fingertip forces during precision gripping and lifting in adults. J Neurosci 1999; 19: 3238-47.

[13] Cole KJ, Rotella DL. Old age affects fingertip forces when restraining an unpredictably loaded object. Exp Brain Res 2001; 136: $535-42$.

[14] Hay L, Bard C, Fleury M, Teasdale N. Availability of visual and proprioceptive afferent messages and postural control in elderly adults. Exp Brain Res 1996; 108: 129-39.

[15] Hurley MV, Rees J, Newham DJ. Quadriceps function, proprioceptive acuity and functional performance in healthy young, middle-aged and elderly subjects. Age Ageing 1998; 27: 55-62.

[16] Madhavan S, Shields RK. Influence of age on dynamic position sense: Evidence using a sequential movement task. Exp Brain Res 2005; 164: 18-28.

[17] Petrella RJ, Lattanzio PJ, Nelson MG. Effect of age and activity on knee joint proprioception. Am J Phys Med Rehabil 1997; 76: 23541.

[18] Romero DH, Van Gemmert AWA, Adler CH, Bekkering H, Stelmach GE. Time delays prior to movement alter the drawing kinematics of elderly adults. Hum Mov Sci 2003; 22: 207-20.

[19] Deschenes MR. Motor unit and neuromuscular junction remodeling with aging. Curr Aging Sci 2011; 4: 209-20.

[20] Shinohara M. Adaptations in motor unit behavior in elderly adults. Curr Aging Sci 2011; 4: 200-8.

[21] Adam A, De Luca CJ, Erim Z. Hand dominance and motor unit firing behavior. J Neurophysiol 1998; 80: 1373-82.

[22] Gandrey P, Paizis C, Karathanasis V, Gueugneau N, Papaxanthis C. Dominant $v s$. nondominant arm advantage in mentally simulated actions in right handers. J Neurophysiol 2013; 110: 2887-94.

[23] Singh T, Zatsiorsky VM, Latash ML. Effects of fatigue on synergies in a hierarchical system. Hum Mov Sci 2012; 31: 137998.

[24] Mathiowetz V, Volland G, Kashman N, Weber K. Adult norms for the box and block test of manual dexterity. Am J Occup Ther 1985; 39: 386-91.

[25] Oldfield RC. The assessment and analysis of handedness: The Edinburgh inventory. Neuropsychologia 1971; 9: 97-113.

[26] Duruöz MT, Poiraudeau S, Fermanian J, et al. Development and validation of a rheumatoid hand functional disability scale that assesses functional handicap. J Rheumatol 1996; 23: 1167-72.

[27] Lefevre-Colau MM, Poiraudeau S, Fermanian J, et al. Responsiveness of the Cochin rheumatoid hand disability scale after surgery. Rheumatology 2001; 40: 843-50.

[28] Du Montcel ST, Charles P, Ribai P, et al. Durr . Composite cerebellar functional severity score: validation of a quantitative score of cerebellar impairment. Brain 2008; 131: 1352-61.

[29] Mathiowetz V, Weber K, Kashman N, Volland G. Adult norms for the nine hole peg test of finger dexterity. Occup Ther J Res 1985; 5: 24-38.

[30] Tamburella F, Scivoletto G, Iosa M, Molinari M. Reliability, validity, and effectiveness of center of pressure parameters in assessing stabilometric platform in subjects with incomplete spinal cord injury: a serial cross-sectional study. J Neuroeng Rehabil 2014; $11: 86$

[31] Shrout PE, Fleiss JL. Intraclass correlations: Uses in assessing rater reliability. Psychol Bull 1979; 86: 420-8.

[32] Portney LG, Watkins MP. Responsiveness to change. In: Portney LG, Watkins MP, Eds. Foundations of clinical research: applications to practice. $2^{\text {nd }}$ edition. New Jersey, USA: Prentice Hall Health, 2000: pp. 103-5. 
[33] Scholtes VA, Terwee CB, Poolman RW. What makes a measurement instrument valid and reliable? Injury 2011; 42: 23640 .

[34] Tavakol M, Dennick R. Making sense of Cronbach's alpha. Int J Med Educ 2011; 2: 53-5.

[35] Chen HM, Chen CC, Hsueh I-P, Huang S-L, Hsieh C-L. Test-retest reproducibility and smallest real difference of 5 hand function tests in patients with stroke. Neurorehabil Neural Repair 2009; 23: 43540.

[36] Fleiss JL, Levin B, Cho Paik M. The measurement of interrater agreement. In: Statistical Methods for Rates and Proportions. $2^{\text {nd }}$ Edition, New York, USA: John Wiley \& Sons, Inc., 1981: pp. 598626.

[37] Nociti V, L. Prosperini, M. Ulivelli, et al. Effects of rehabilitation treatment of the upper limb in Multiple Sclerosis patients and predictive value of neurophysiological measures. Eur J Phys Rehabil Med 2016 [Epub ahead of print].

[38] Lam NW, Goh HT, Kamaruzzaman SB, Chin AV, Poi PJ, Tan MP. Normative data for hand grip strength and key pinch strength, stratified by age and gender for a multiethnic Asian population. Singapore Med J 2016; 57: 578-84.

[39] Günther CM, Bürger A, Rickert M, Crispin A, Schulz CU. Grip strength in healthy caucasian adults: reference values. J Hand Surg Am 2008; 33: 558-65.

[40] Härkönen R, Piirtomaa M, Alaranta H. Grip strength and hand position of the dynamometer in 204 Finnish adults. J Hand Surg Br 1993; 18: 129-32.

[41] Lawrence EL, Fassola I, Werner I, Leclercq C, Valero-Cuevas FJ. Quantification of dexterity as the dynamical regulation of instabilities: comparisons across gender, age, and disease. Front Neurol 2014; $5: 53$.

[42] Shinohara M, Li S, Kang N, Zatsiorsky VM, Latash ML. Effects of age and gender on finger coordination in MVC and submaximal force-matching tasks. J Appl Physiol 2003; 94(1): 259-70.

[43] Ingalhalikar M, Smith A, Parker D, et al. Sex differences in the structural connectome of the human brain. Proc Natl Acad Sci U S A 2014; 111: 823-8.

[44] Rodríguez-Aranda C, Mittner M, Vasylenko O. Association between executive functions, working memory, and manual dexterity in young and healthy older adults: An exploratory study. Percept Mot Skills 2016; 122: 165-92.

[45] Diermayr G, McIsaac TL, Kaminski TR, Gordon AM. Aging effects on object transport during gait. Gait Posture 2011; 34: 3349 .

[46] Ketcham CJ, Seidler RD, Van Gemmert AWA, Stelmach GE. Agerelated kinematic differences as influenced by task difficulty, target size, and movement amplitude. J Gerontol B Psychol Sci Soc Sci 2002; 57: 54-64.

[47] Bilodeau-Mercure M, Kirouac V, Langlois N, Ouellet C, Gasse I, Tremblay P. Movement sequencing in normal aging: speech, orofacial, and finger movements. Age 2015; 37: 78.
[48] Fama R, Sullivan EV. Motor sequencing in Parkinson's disease: Relationship to executive function and motor rigidity. Cortex 2002; 38: 753-67.

[49] Curcio F, Ferro G, Basile, C, et al. Biomarkers in sarcopenia: A multifactorial approach. Exp Gerontol 2016; 85: 1-8.

[50] Halilaj E, Moore DC, Laidlaw DH, et al. The morphology of the thumb carpometacarpal joint does not differ between men and women, but changes with aging and early osteoarthritis. J Biomech 2014; 47: 2709-14.

[51] Oxford Grice K, Vogel KA, Le V, Mitchell A, Muniz S, Vollmer MA. Adult norms for a commercially available nine hole peg test for finger dexterity. Am J Occup Ther 2003; 57: 570-3.

[52] Tzourio-Mazoyer N, Petit L, Zago L, et al. Mazoyer. Betweenhand difference in ipsilateral deactivation is associated with hand lateralization: fMRI mapping of 284 volunteers balanced for handedness. Front Hum Neurosci 2015; 9: 5.

[53] Gabay O, Gabay C. Hand osteoarthritis: New insights. Joint Bone Spine 2013; 80: 130-4

[54] Kwok WY, Kloppenburg M, Marshall M, Nicholls E, Rosendaal FR, Peat G. The prevalence of erosive osteoarthritis in carpometacarpal joints and its clinical burden in symptomatic community-dwelling adults. Osteoarthritis Cartilage 2014; 22: 75663.

[55] Ramonda R, Frallonardo P, Musacchio E, Vio S, Punzi L. Joint and bone assessment in hand osteoarthritis. Clin Rheumatol 2014; 33 : $11-9$

[56] Calfee R, Chu J, Sorensen A, Martens E, Elfar J. What is the impact of comorbidities on self-rated hand function in patients with symptomatic trapeziometacarpal arthritis? Clin Orthop Relat Res 2015; 473: 3477-83.

[57] Van Onna M, Boonen A. The challenging interplay between rheumatoid arthritis, ageing and comorbidities. BMC Musculoskelet Disord 2016; 17: 184.

[58] Krukhaug Y, Lie SA, Havelin LI, Furnes O, Hove LM, Hallan G. The results of 479 thumb carpometacarpal joint replacements reported in the Norwegian Arthroplasty Register. J Hand Surg Eur Vol 2014; 39: 819-25.

[59] Owings FP, Calandruccio JH, Mauck BM. Thumb ligament injuries in the athlete. Orthop Clin North Am 2016; 47: 799-807.

[60] Gilman L, Cage DN, Horn A, Bishop F, Klam WP, Doan AP. Tendon rupture associated with excessive smartphone gaming. JAMA Intern Med 2015; 175: 1048

[61] İnal EE, Demİrcİ K, Cetİntürk A, Akgönül M, Savaş S. Effects of smartphone overuse on hand function, pinch strength, and the median nerve. Muscle Nerve 2015; 52: 183-8.

[62] Birren JE, Fisher LM. Aging and speed of behavior: possible consequences for psychological functioning. Annu Rev Psychol 1995 46: 329-53.

[63] Clark BC, Taylor JL. Age-related changes in motor cortical properties and voluntary activation of skeletal muscle. Curr Aging Sci 2011; 4: 192-9. 